\title{
IMPROVED QUALITY AND ECONOMICS OF INVESTMENT CASTINGS BY LIQUID METAL COOLING - THE SELECTION OF COOLING MEDIA
}

\author{
A. Lohmüller ${ }^{1}$, W. Eßer ${ }^{2}$, J. Großmann ${ }^{3}$, M. Hördler ${ }^{1}$, J. Preuhs ${ }^{3}$ and R. F. Singer ${ }^{1}$, \\ ${ }^{1}$ Lehrstuhl Werkstoffkunde und Technologie der Metalle (WTM), 91058 Erlangen, Germany \\ ${ }^{2}$ Siemens KWU, 45473 Mülheim a. d. Ruhr, Germany \\ ${ }^{3}$ DONCASTERS Precision Castings - Bochum GmbH (DPC), 44793 Bochum, Germany
}

Introduction

\begin{abstract}
A new directional solidification technique promising a more economic production of large blades is the Liquid-Metal-Cooling (LMC) process. The advantages of this technique are summarized in the papcr. Dircet temperature measurements as well as microstructural comparisons point towards an increase of the thermal gradient by a factor of two for large industrial turbine blades. This is at the present state of technical development, i.e. further improvements are expected eventually.

One of the most important factors in optimizing LMC is the choice of the cooling medium. In this paper tin and aluminium are compared. The advantages and disadvantages of these two cooling media are discussed in detail. Special attention is directed to the heat transfer potential and the possible dissolution of the cast component in the cooling bath in case of inadvertant contact. In addition information on the effect of tin as an intentional alloying element is given. Although tin looks rather favourable with respect to the points discussed, the long term performance on an industrial scale as compared to aluminium remains to be seen.
\end{abstract}

Higher demands on turbine blades in modern industrial gas turbines (IGT's) have led to increasing use of directional solidification. The trend towards larger components and more complex alloy compositions reveales the limitations of the conventional Bridgman-technique (High-Rate-Solidification technique, HRS). Due to the limited temperature gradient only low withdrawal rates can be applied. An economic production based on radiation cooling becomes therefore quite difficult [1]. A promising alternative is the Liquid-Metal-Cooling (LMC) process $[2,3]$. LMC is expected to provide important improvements and may play a significant role in the industry in the near future [4].

The main advantages of the LMC technique have been well demonstrated for small scale, laboratory test pieces [5]. The higher thermal gradient and the increased solidification rate results in a finer microstructure as compared to the conventional Bridgmantechnique. This reduces significantly the solution heat treatment soak period.

Superalloys 2000

Edited by T.M. Pollock, R.D. Kissinger, R.R. Bowman,

K.A. Green, M. McLean, S. Olson, and J.J. Schirra

TMS (The Minerals, Metals \& Materials Society), 2000 


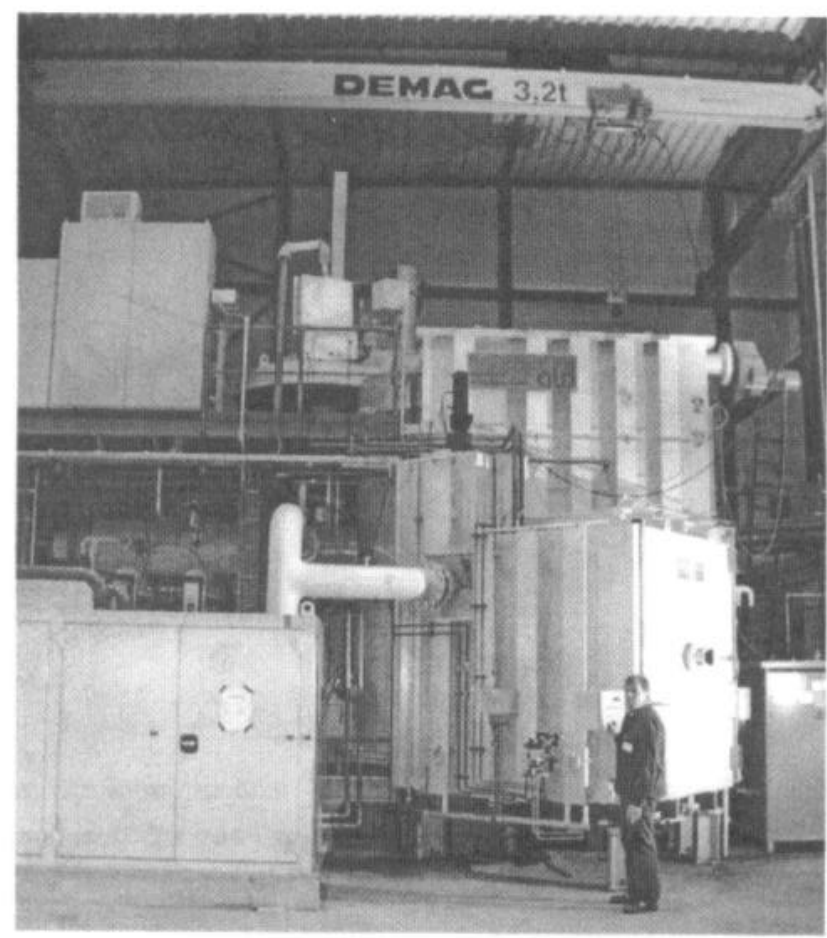

Figure 1: Industrial scale LMC-furnace at DONCASTERS Precision Castings - Bochum GmbH, Germany. This furnace is in operation since mid of 1999.

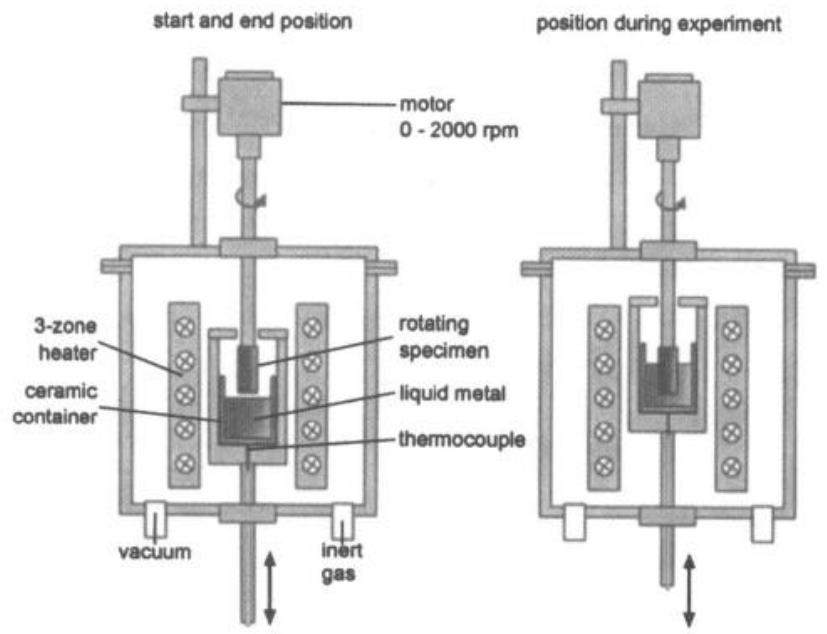

Figure 2: Schematic diagram of the apparatus used for the immersion and dissolution tests. During heating to temperature $\mathrm{T}$ the specimen and the liquid metal are not in contact (left). During the time $t$ the rotating specimen is immersed into the liquid metal bath (right).
In 1994, a LMC pilot plant was installed at the WTM-institute in Erlangen [3]. By casting large test pieces and full scale, cored IGT single crystal turbine blades the feasibility of LMC was studied on a prototype scale. Some results from this program will be presented in the following together with some more general considerations that led recently to the construction of the worlds largest LMC production scale furnace (Figure 1) at DONCASTERS Precision Casting in Bochum. The main emphasis of the paper will be on the choice of a suitable cooling medium in LMC.

\section{Experimental Procedure}

LMC-casting trials have been carried out in the pilot plant at the WTM-Institute. The cooling bath with dimensions of $700 \mathrm{~mm} \mathrm{x}$ $700 \mathrm{~mm} \times 700 \mathrm{~mm}$ contains $1.7 \mathrm{t}$ of liquid tin. Single crystal slabs (18 mm x $100 \mathrm{~mm} \times 200 \mathrm{~mm}$, two slabs per mold) and full scaled, cored IGT single crystal turbine blades were cast. The nickel base superalloys SC16 (16 wt.\% Cr, 3,5 \% Al, 3,5\% Ta, 3,5\% Ti, $3 \% \mathrm{Mo}$ and $\mathrm{Ni}$ as balance) and PWA $1483(12,2 \% \mathrm{Cr}, 9 \% \mathrm{Co}$, $4,1 \% \mathrm{Ti}, 3,6 \% \mathrm{Al}, 1,9 \% \mathrm{Mo}, 3,8 \% \mathrm{~W}, 5 \% \mathrm{Ta}, 0,07 \% \mathrm{C}$ and $\mathrm{Ni}$ as balance) were used. The test pieces were solution heat treated and aged before mechanical testing.

In order to investigate the behaviour of the superalloys in direct contact with the cooling medium a laboratory test was developed (see Figure 2). A cylindrical, polished superalloy specimen (10 mm diameter) is immersed into a liquid metal bath (tin or aluminium) at constant temperature for an appropriate time. The specimen can be rotated at different speeds. In order to obtain reacting surfaces with well defined uniform flow conditions in the bath, the cylinder is coated at the bottom and near the fluid surface. In this way these surfaces are protected against dissolution. The bulk concentration $c_{t}$ at the time $t$ is calculated from the weight loss of the specimen.

\section{$\underline{\text { Results }}$}

\section{Advantages of the Liquid Metal Cooling-technique}

Higher thermal gradients. It has always been assumed that the LMC-process has the advantage of producing a higher longitudinal thermal gradient during solidification. In the following, we want to explore the evidence for this when large IGT-geometries are considered. 
The potential of the LMC process on a larger scale has been studied in an earlier investigation using an analytical model $[6,7]$. It was possible to predict the optimal withdrawal rate and the temperature gradient. Predominantly in large cross sections LMC was expected to double the gradient as compared to the HRStechnique. The influence of several parameters like temperature of the heater and the cooling medium, ceramic shell conductivity or mold thickness were examined. Depending on the parameter set, thermal gradients for LMC in the range between $2 \mathrm{~K} / \mathrm{mm}$ and $8 \mathrm{~K} / \mathrm{mm}$ were calculated.

The results of the earlier theoretical investigation will be now compared with the experimental results. At first we will derive the thermal gradient by evaluating the microstructure achieved during solidification for casting conditions that are typical for each process. In a first stage turbine blade (length $\approx 290 \mathrm{~mm}$ ) LMC was found to reduce the primary dendrite arm spacing $\lambda_{1}$ by half [8]. $\Lambda t$ the same time LMC allows withdrawal rates twice as high as the HRS technique [8]. The use of the empirical formula [9]

$$
\lambda_{\mathrm{I}}=750 \mathrm{G}^{-\frac{1}{2}} \mathrm{v}^{-\frac{1}{4}}
$$

allows to estimate the temperature gradient present. For the HRStechnique $\left(\lambda_{1} \approx 600 \mu \mathrm{m}, \mathrm{v}=3.5 \mathrm{~mm} / \mathrm{min}\right)$ a gradient of $\mathrm{G}_{\mathrm{HRS}}=0.8$ $\mathrm{K} / \mathrm{mm}$ can be calculated, while for LMC $\left(\lambda_{1} \approx 300 \mu \mathrm{m}\right.$, $\mathrm{v}=8.0 \mathrm{~mm} / \mathrm{min}$ ) the gradient is $\mathrm{G}_{\mathrm{IMC}}=2.2 \mathrm{~K} / \mathrm{mm}$. It must be

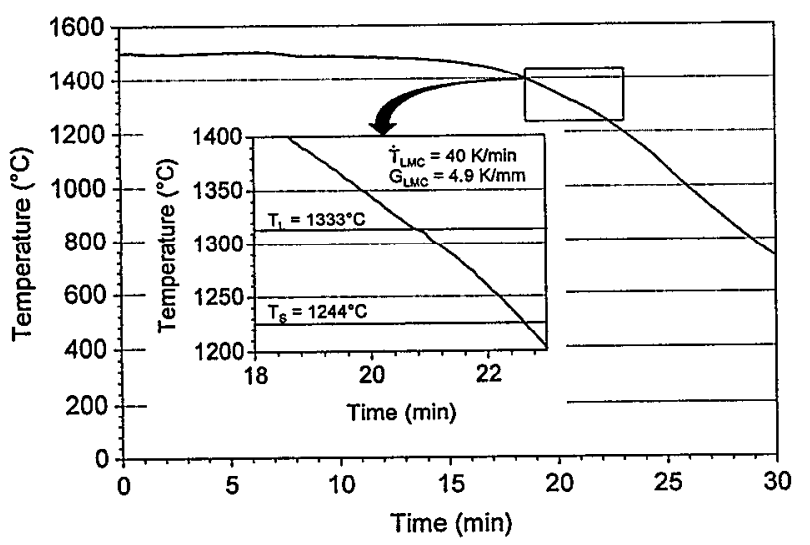

Figure 3: Cooling curve during withdrawal for an IGT blade (length $\approx 290 \mathrm{~mm}$ ) solidified at a withdrawal rate of $8 \mathrm{~mm} / \mathrm{min}$ using the LMC pilot plant at WTMInstitute. The thermocouple was situated in the middle of the airfoil. The thermal gradient is determined to be $4.9 \mathrm{~K} / \mathrm{mm}$. This value is in good agreement with values derived from evaluation of the microstructure as well as earlier analytical predictions. It is at least twice as high as in the corresponding HRS process. noted, however, that the experimental data in [9] shows a large scatter. Therefore, the gradient is better represented by a range, e.g. from $1.5 \mathrm{~K} / \mathrm{mm}$ to $3.8 \mathrm{~K} / \mathrm{mm}$ for $\mathrm{LMC}$ and $0.7 \mathrm{~K} / \mathrm{mm}$ to $1.1 \mathrm{~K} / \mathrm{mm}$ for HRS.

To confirm the estimates based on the microstructure, temperature measurements with thermocouples have been performed during the LMC-process. Figure 3 shows a cooling curve for a first stage turbine blade in the middle of the airfoil. The cooling rate at the liquidus front was determined to be $40 \mathrm{~K} / \mathrm{min}$. For a withdrawal ratc of $8 \mathrm{~mm} / \mathrm{min}$ this is equivalent to a thermal gradient of $4.9 \mathrm{~K} / \mathrm{mm}$ which is somewhat higher but close to the values based on equation (1).

Other LMC advantages. The LMC process has further advantages besides its capability for higher gradients. Higher withdrawal rates and reduced dendrite arm spacings have already been mentioned. In addition LMC-cast components show finer and more homogeneously distributed carbide precipitates and $\gamma / \gamma^{\prime}$-eutectic. The $\gamma^{6}$-precipitates are distributed more uniformly and cubic morphology is already achieved in the as cast condition. Due to the smaller dendrite arm spacings, concentration gradients are much higher and segregation is much more rapidly eliminated. The high temperature gradients can be achieved even for large blade clusters, since heat transfer is uniform even under these conditions. [8]

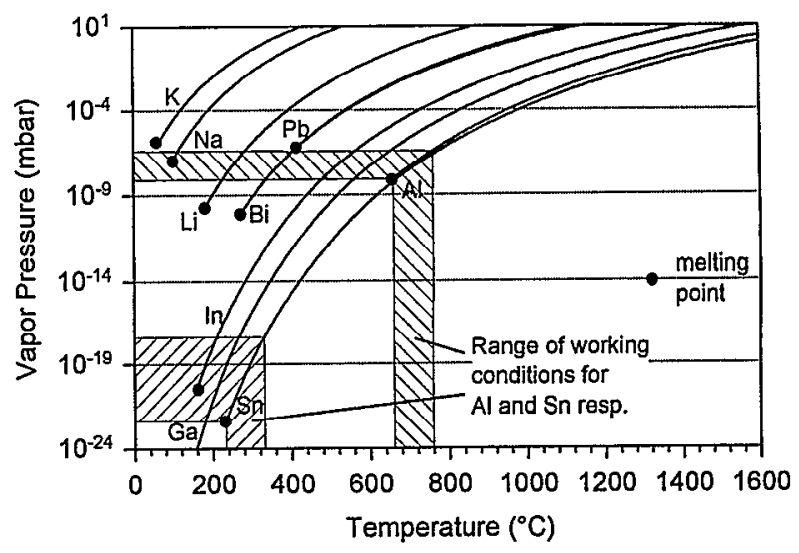

Figure 4: Vapor pressure of low melting point metals [18]. A low vapor pressure is a prerequisite for use as cooling medium in the LMC process. Both tin and aluminium are particularly suitable. 
Physical properties and heat transfer. One of the challenges in the optimization of the LMC technology on an industrial scale is to find a suitable cooling medium. Several requirements have to be fullfilled e.g. low melting temperature, low vapor pressure, high thermal conductivity, low viscosity, no toxicity, and economic efficiency.

Figure 4 presents the vapor pressure of low melting point metals as a function of temperature. The only liquid metals with suitable vapor pressure for a vacuum process at high temperatures are aluminium and tin. Gallium and indium are not considered due to their high price. Although the curves for aluminium and tin are nearly congruent, tin appears to be more favourable because the lower melting point allows a lower process temperature to be used.

One of the evident advantages of aluminium is its very high thermal conductivity $\left(\lambda=104 \mathrm{~W} / \mathrm{mK}\right.$ at a temperature of $\left.660^{\circ} \mathrm{C}\right)$ promising a good heat transfer from the casting, see Table $\mathrm{I}$. However there are other important factors in heat transfer that should not be overlooked. A simple pseudo-one-dimensional heat transfer model can give an idea of the magnitude of the heat flux possible. The situation is depicted in the insert drawing in Figure 5. For every temperature $T_{S C}$ within the solidified cast component a local heat flux q perpendicular to the withdrawal direction can be calculated. The heat is transferred through a gap between the

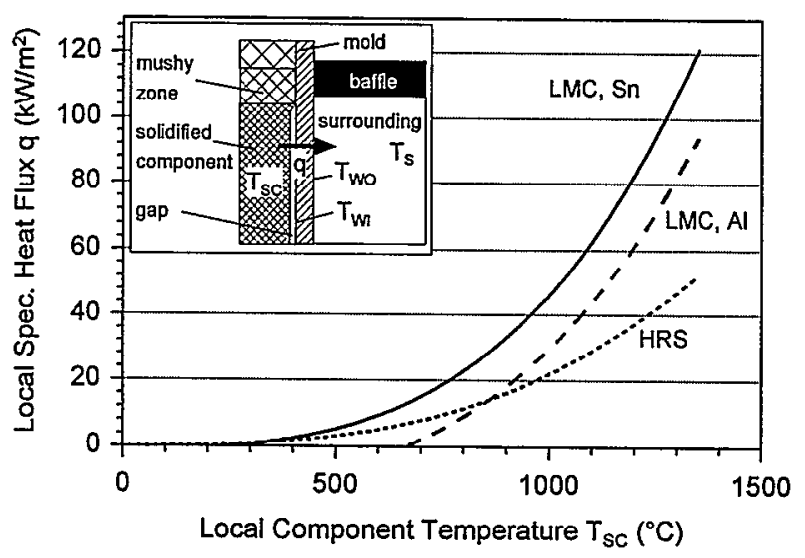

Figure 5: Comparison of the calculated local specific hcat flux $\mathrm{q}$ for LMC with tin or aluminium as a cooling medium with the conventional HRS-technique. The heat flux for LMC with tin is significantly higher than for LMC with Aluminium. In general LMC leads to better cooling conditions than the HRS-technique.
Table I: Properties of liquid aluminium and liquid tin at their melting point [19].

\begin{tabular}{|l|l|c|c|}
\hline Property & Unit & Aluminium & Tin \\
\hline Melting point & ${ }^{\circ} \mathrm{C}$ & 660 & 232 \\
\hline Density & $\mathrm{kg} / \mathrm{m}^{3}$ & 2382 & 6980 \\
\hline Specific heat & $\mathrm{kJ} / \mathrm{m}^{3} \mathrm{~K}$ & 2597 & 1857 \\
\hline Thermal conductivity & $\mathrm{W} / \mathrm{mK}$ & 104 & 33.5 \\
\hline Thermal diffusivity & $\mathrm{m}^{2} / \mathrm{s}$ & $40 \times 10^{-6}$ & $18 \times 10^{-6}$ \\
\hline Latent heat & $\mathrm{kJ} / \mathrm{m}^{3}$ & 921834 & 418800 \\
\hline Kinematic Viscosity & $\mathrm{m}^{2} / \mathrm{s}$ & $6,3 \times 10^{-7}$ & $2,58 \times 10^{-7}$ \\
\hline
\end{tabular}

cast component and the inner mold surface at temperature $\mathrm{T}_{\mathrm{WI}}$ by radiation. It was assumed that the heat transfer takes place between two infinite parallel plates [10]. For heat transfer through the shell wall (with thermal conductivity $\lambda_{\text {md }}=4 \mathrm{~W} / \mathrm{mK}$ and thickness $d_{m d}=10 \mathrm{~mm}$ ) by conduction and heat transport from the outer mold surface at temperature $\mathrm{T}_{\mathrm{wo}}$ into the surrounding liquid metal bath at temperature $T_{S}$ by convection the overall heat balance takes the following form:

$$
\mathrm{q}=\frac{\sigma \mathrm{T}_{\mathrm{SC}}^{4}-\sigma \mathrm{T}_{\mathrm{WI}}^{4}}{\frac{1}{\varepsilon_{1}}+\frac{1}{\varepsilon_{2}}-1}=\frac{\lambda_{\text {md }}}{\mathrm{d}_{\mathrm{md}}}\left(\mathrm{T}_{\mathrm{WI}}-\mathrm{T}_{\mathrm{WO}}\right)=\alpha\left(\mathrm{T}_{\mathrm{WO}}-\mathrm{T}_{\mathrm{S}}\right)
$$

with $\varepsilon_{1}=\varepsilon_{2}=0.5$. The heat transfer coefficient $\alpha$ can be calculated, e.g. for flow over a flat plate, using the following formula [11]:

$$
\mathrm{Nu}=\frac{\alpha \mathrm{L}}{\lambda_{\mathrm{f}}}=0,38(\operatorname{Re} \operatorname{Pr})^{0,65}=0,38\left(\frac{\mathrm{U}_{\mathrm{f}} \mathrm{L}}{v_{\mathrm{f}}} \operatorname{Pr}\right)^{0,65}
$$

where $\mathrm{Nu}$ is the Nusselt-number, $\mathrm{Re}$ is the Reynolds-number and $\mathrm{Pr}$ is the Prantl-number. Figure 5 shows the local heat flux $q$ according to eq. (2) for an alloy with a liquidus temperature of $1350^{\circ} \mathrm{C}$ for both cooling media, aluminium $\left(T_{S}=660^{\circ} \mathrm{C}\right)$ and tin $\left(T_{S}=232^{\circ} \mathrm{C}\right)$. A flow velocity of $U_{f}=0.1 \mathrm{~m} / \mathrm{s}$ and a characteristic length of $\mathrm{L}=0.1 \mathrm{~m}$ for the cast component was assumed.

The most important parameter determining the heat flux in LMC is the temperature of the surrounding medium. Therefore, the heat flux with tin is significantly higher than with aluminium.

In addition, a curve for heat transport by radiation from the outer mold surface is given in Figure 5:

$$
\mathrm{q}=\frac{\sigma \mathrm{T}_{\mathrm{SC}}^{4}-\sigma \mathrm{T}_{\mathrm{WI}}^{4}}{\frac{1}{\varepsilon_{1}}+\frac{1}{\varepsilon_{2}}-1}=\frac{\lambda_{\mathrm{md}}}{\mathrm{d}_{\mathrm{md}}}\left(\mathrm{T}_{\mathrm{WI}}-\mathrm{T}_{\mathrm{WO}}\right)=\frac{\sigma \mathrm{T}_{\mathrm{WO}}^{4}-\sigma \mathrm{T}_{\mathrm{S}}^{4}}{\frac{1}{\varepsilon_{1}}+\frac{1}{\varepsilon_{2}}-1}
$$


with $\varepsilon_{1}=\varepsilon_{2}=0.5$ and $\mathrm{T}_{\mathrm{S}}=25^{\circ} \mathrm{C}$. It is obvious that the heat flux for both LMC-techniques is much higher than for the HRSprocess.

There are other properties in Table I that have to be taken into account. For example the density of aluminium is only one third of tin thus faciliting contruction problems. On the other hand the energy $\Delta \mathrm{E}$ needed for melting the cooling medium:

$$
\Delta \mathrm{E}=\int_{\mathrm{RT}}^{\mathrm{T}_{\mathrm{S}}} \mathrm{C}_{\mathrm{P}} \mathrm{dT}+\Delta \mathrm{H}
$$

is more than $250 \%$ higher for aluminium $\left(\Delta \mathrm{E}=2.47 \times 10^{6} \mathrm{~kJ} / \mathrm{m}^{3}\right)$ than for tin $\left(\Delta \mathrm{E}=0.68 \times 10^{6} \mathrm{~kJ} / \mathrm{m}^{3}\right)$.

Mechanical properties and effect of tin. A particularly important issue is the possible contamination of the superalloy with the cooling medium, e.g. when revert material is used. For aluminium, which is an alloying element in nickel base superalloys, this is not an issue. In the case of tin a review of the literature shows that tin is generally believed to be harmful. The removal of tin from the alloy using long melting times during production of the master melt is not possible [13, 14]. In order to clarify the effect of tin on alloy properties, test slabs with tin concentrations up to $4150 \mathrm{ppm}$ were cast and heat treated. Creep rupture strength was tested for SC16 and PWA 1483.

A Larson-Miller-plot for SC16 with and without tin additions (Figure 6) illustrates that there is no important influence of tin on the creep strength. Creep rupture tests for PWA 1483 showed that this holds even for very high tin concentrations up to $4150 \mathrm{ppm}$ that are extremely unlikely to occur in commercial practice. In Figure 7 SEM-micrographs of the microstructure of SC16 with and without tin doping are shown. There is no apparent effect of

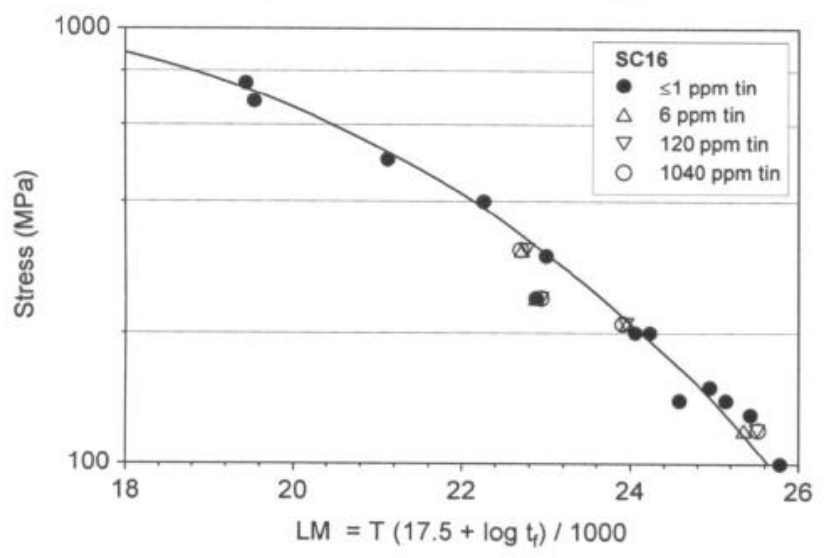

Figure 6: Creep strength of single crystal superalloy SC16. The Larsen-Miller parameter LM was calculated using temperature $\mathrm{T}$ in Kelvin and time $\mathrm{t}_{\mathrm{f}}$ in hours. There is no important influence of added tin.
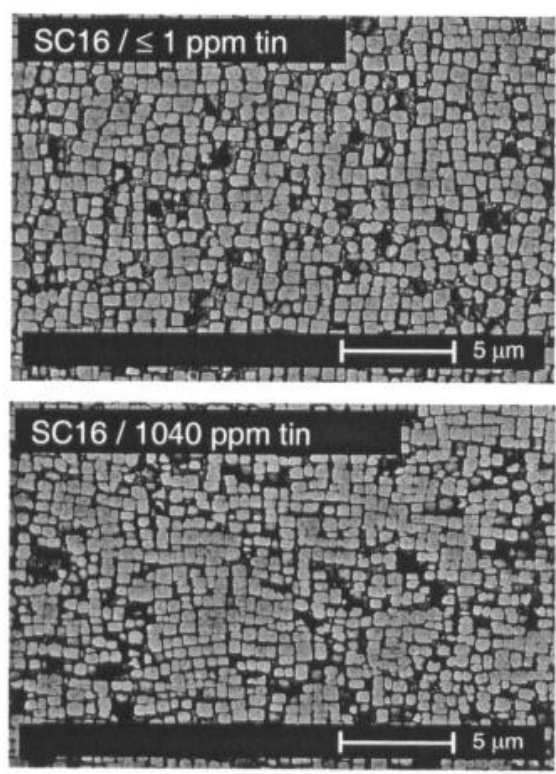

Figure 7: SEM-micrographs of the microstructure of SC16 with and without tin doping. There is no apparent effect of tin on shape, size or volume fraction of the $\gamma^{4}$-precipitates.

tin on shape, size or volume fraction of the $\gamma^{4}$-precipitates.

In addition low cycle fatigue has been tested for PWA 1483 with the same tin concentrations. In Figure 8 the results for $850^{\circ} \mathrm{C}$ and $950^{\circ} \mathrm{C}$ are presented. Again no influence on the mechanical properties was determined. The evaluation of other properties like corrosion resistance is presently under way.

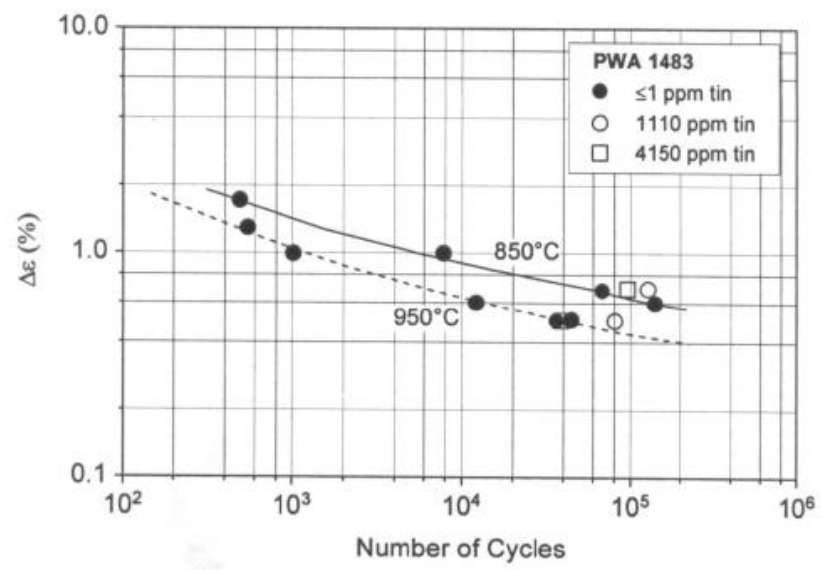

Figure 8: Low cycle fatigue strength of the single crystal superalloy PWA 1483. No significant influence of tin is found. 

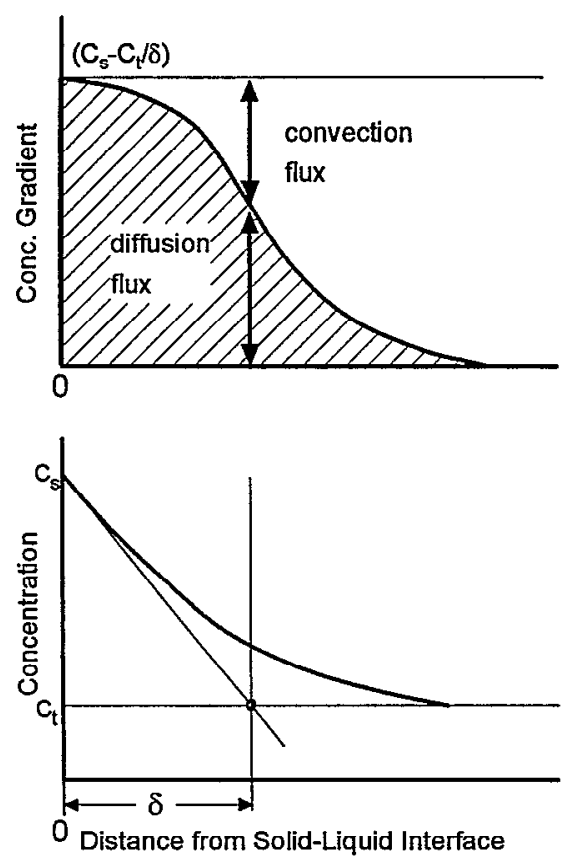

Figure 9: Schematic representation of the concentration profile in the case of the dissolution of a solid substance in a liquid. At the interface diffusive flux is rate limiting $[15,16]$.

Alloy dissolution. Further difficulties may appear if the solidified superalloy comes inadvertently into contact with the cooling medium. Reactions with the liquid metal of the cooling bath could lead to partial dissolution of the cast component. A related issue is the reaction between the liquid metal of the cooling bath and the bath container material and other bath components.

Several transport mechanisms might be limiting for the reaction rate in alloy dissolution, e.g. diffusion in the solid, mass transfer between solid and liquid, or the transport within the fluid. For the sake of the argument, let us assume in the following transport in the liquid phase limits the rate of the dissolution. The transport in the fluid occurs through a combination of diffusion and convection (see Figure 9) $[15,16]$. The total flux is constant and does not change with the distance from the solid-liquid interface. Near the interface transport is by diffusion while further in the bulk convection becomes dominant. A boundary layer thickness $\delta$ can be defined as shown in Figure 9. Considering Fick's law and the time dependence of the diffusion flux, the rate of dissolution can be calculated by using the differential equation

$$
\frac{\mathrm{dc}}{\mathrm{dt}}=\mathrm{D} \frac{\mathrm{A}}{\mathrm{V}} \frac{\mathrm{c}_{\mathrm{s}}-\mathrm{c}}{\delta}
$$

where $\mathrm{D}$ is the diffusion coefficient, $\mathrm{V}$ is the liquid metal volume, $A$ is the area of the solid-liquid interface, $c$ is the bulk concentration of the liquid metal bath and $c_{s}$ is the saturation concentration. For a transport controlled, one-dimensional reaction the solution of (6) can be given as:

$$
c_{t}=c_{s}\left[1-\exp \left(-\frac{D}{\delta} \frac{A}{V} t\right)\right]
$$

The term $\mathrm{D} / \delta$ can be substituted by a solution rate constant $\mathrm{k}$. The thickness of the boundary layer $\delta$ and therefore the constant $\mathrm{k}$ depends on the flow conditions.

Using a laboratory test with a cylindrical specimen rotating in a liquid metal bath (Figure 2) it was possible to investigate the kinetics of the dissolution of superalloys in liquid metals at various temperatures. Some results for the system SC16-Sn at $1000^{\circ} \mathrm{C}$ are presented in Figure 10. It is obvious that for a rotational speed of $80 \mathrm{rpm}$ (Reynolds number $\operatorname{Re}=\mathrm{n} \mathrm{d}^{2} / \mathrm{v}=620$ ) corresponding to a laminar fluid flow there is only little difference to the static case, while a rotational speed of $300 \mathrm{rpm}(\operatorname{Re}=2325)$ corresponding to a turbulent flow leads to a very fast dissolution. Higher rotating speeds lead to higher degrees of convection and therefore smaller boundary layers. The evident influence of the flow conditions in the bath is an indication for transport within the fluid to be limiting, rather than diffusion in the solid.

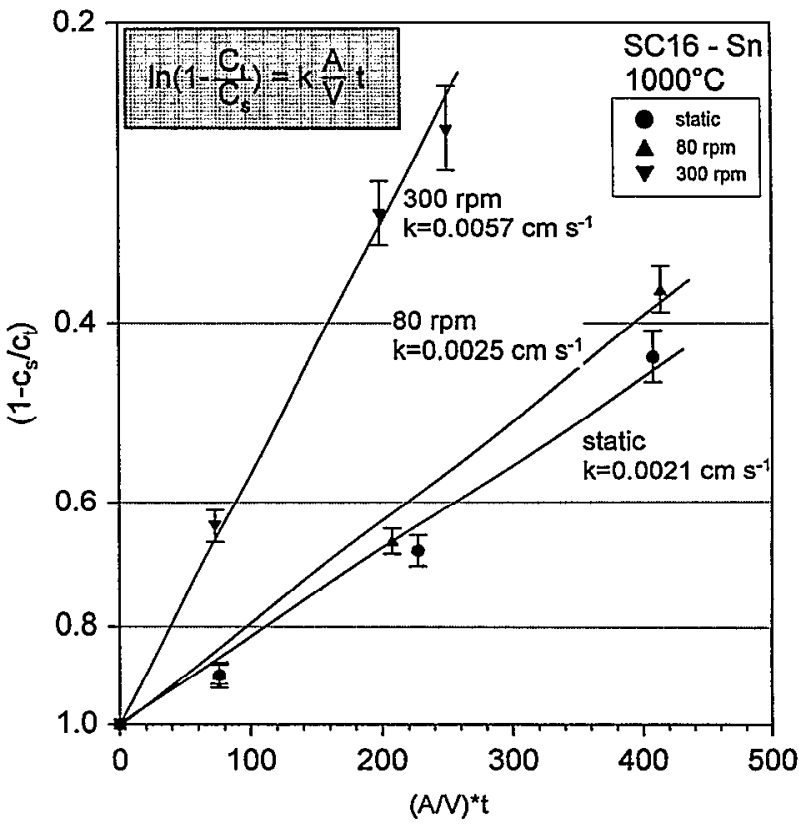

Figure 10: Plot of $\ln \left(1-c / c_{s}\right)$ as a function of $(A / V) t$ for dissolution of superalloy SC16 in liquid tin, see equation (7) in the text. The slope of the curve is equivalent to the solution rate constant $k$. Stirring obviously speeds up the dissolution of the superalloy, thus confirming that transport in the bath is rate controlling. 
Experiments at different temperatures and equal flow conditions allow to determine the activation energy $\Delta \mathrm{H}$ using the formula:

$$
\mathrm{k}=\mathrm{k}_{0} \mathrm{e}^{-\frac{\Delta \mathrm{H}}{\mathrm{RT}}}
$$

Figure 11 shows an Arrhenius-plot for the dissolution of SC16 in liquid tin. The activation energy is determined to be $56 \mathrm{~kJ} / \mathrm{mol}$. This rather low value is another indication that transport in the liquid is rate controlling. It is similar to other values found in the literature for dissolution of metals in liquids, where diffusion in the liquid controls the reaction rate. Processes like dissolution of silver in mercury $(\Delta \mathrm{H}=59.4 \mathrm{~kJ} / \mathrm{mol})$ [16] or of chromium in iron $(\Delta \mathrm{H}=44.8 \mathrm{~kJ} / \mathrm{mol})[17]$ are examples.

With respect to the dissolution of a superalloy, tin and aluminium will be compared below at their respective process temperatures. Figure 12 shows that an aluminium melt at $700^{\circ} \mathrm{C}(40 \mathrm{~K}$ above aluminium melting point) leads to considerable damage after only 15 minutes. For tin at $300^{\circ} \mathrm{C}(68 \mathrm{~K}$ above its melting point) no reaction is observed at all even after 300 minutes direct contact.

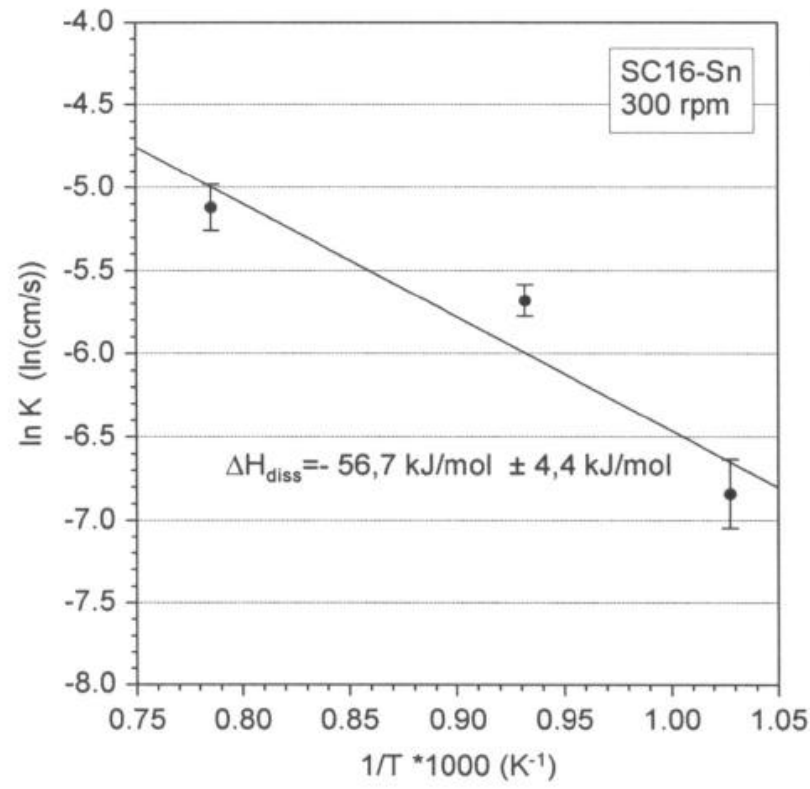

Figure 11: Arrhenius-plot for the solution rate constant $k$ for SC16 in liquid tin. Specimens were rotated with $300 \mathrm{rpm}$. The activation energy was determined to be $56 \mathrm{~kJ} / \mathrm{mol}$ which is typical for diffusion in the liquid metal to be rate limiting.

\section{$\underline{\text { Conclusions }}$}

The Liquid Metal Cooling (LMC) process has several advantages in comparison with the conventional Bridgman-technique (high rate solidification, HRS). The rapid and uniform heat transfer allows higher withdrawal rates and larger clusters. At the same time a finer and more homogeneous microstructure is obtained.

An important factor for commercializing the process is the choice of the cooling medium. The discussion of the physical properties focusses on the two cooling media aluminium and tin. A heat balance shows the improved potential with both cooling media in comparison with the HRS-process. The maximum heat flux for tin was calculated to be significantly higher than for aluminium.

Measurements of the creep strength and low cycle fatigue strength for SC16 and PWA 1483 showed that intentional doping of the alloys with up to $4150 \mathrm{ppm}$ tin has no significant influence on the mechanical properties.

Direct contact between the cast component and the cooling medium was examined. Diffusion in the fluid was found to be the limiting mechanism for a dissolution of the superalloy in the liquid metal. Tin and aluminium were compared at typical process temperatures. No reaction is observed for tin $\left(300^{\circ} \mathrm{C}\right)$ after $300 \mathrm{~min}$ while aluminium $\left(700^{\circ} \mathrm{C}\right)$ causes significant dissolution of the superalloy after $15 \mathrm{~min}$.

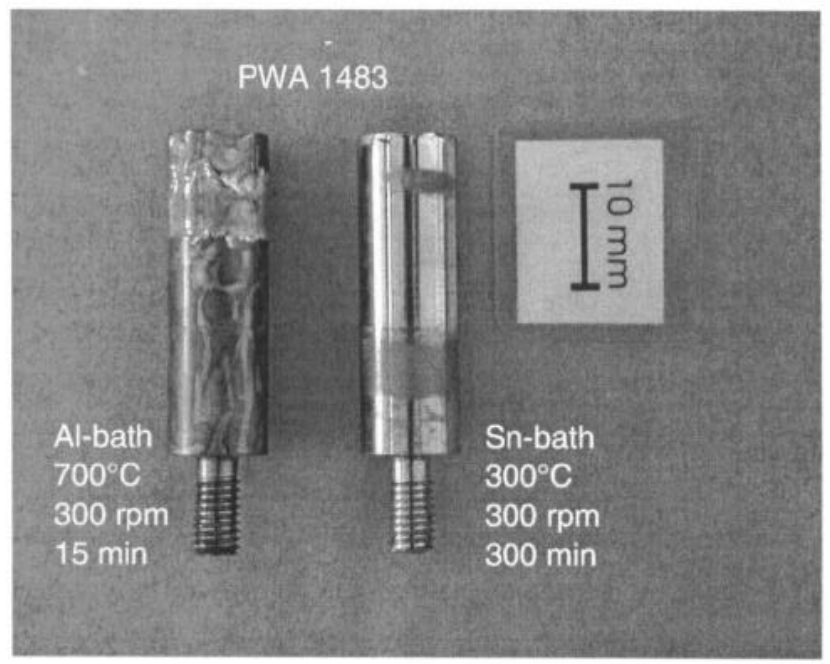

Figure 12: Comparison of dissolution of PWA 1483 in liquid aluminium or tin at typical process temperatures. No superalloy dissolution is apparent with tin, whereas significant dissolution occurs with aluminium. 


\section{References}

1. M. Konter, N. Hoffmann, C. Tönnes, M. Newnham: "Influence of a Casting Process with High Cooling Rate on Structure and Properties of SX and DS components for Industrial Gas Turbines", (Paper presented at the $3^{\text {rd }}$ ALD Symposium, Frankfurt, Nov. 1995)

2. J.S. Erickson, C.P. Sullivan, F.L. Versnyder, "Modern processing methods and investment casting of the superalloy family", in: High Temperaturc Materials in Gas Turbines, (ed. P.R. Sahm, M.O. Speidel), (New York, American Elsevier Publishing Company, 1974), pp. 315-340

3. R.F. Singer, "Advanced Materials and Processes for landbased Gas Turbines", in: Materials for Advanced Power Engineering, Part II (ed. D. Coutsousadis et al.), (Dordrecht, Kluwer Academic Press, 1994), pp.1707-1729

4. S. Olson, "A Market Forecast for Land-Based Gas Turbines \& Superalloy Applications", (Paper presented at Superalloys 99, Gorham's Int. Business Conf., San Antonio, Texas, Nov. 1999)

5. A.F. Giamci, J.G. Tschinkel, "Liquid Metal Cooling: A New Solidification Technique", Met. Trans. A, Vol 7A (1976), pp. $1427-1434$

6. T.J. Fitzgerald, R.F. Singer, "An Analytical Model for Optimal Directional Solidification using Liquid Metal Cooling", Met. Trans. A, Vol 28A (1997), pp. 1377-1383

7. T.J. Fitzgerald, R.F. Singer, "Modeling of the Directional Solidification of Turbine Blades via Liquid Metal Cooling", in: Proc. 2nd Pacific Rim Int. Conf. On Mod. of Cast. and Solid. Proc., E. Niyama \& H. Kodama, eds., (Hitachi Ltd., Hitachi, 1995), pp. 201-216

8. J. Großmann, J. Preuhs, W. Eßer, R. F. Singer, "Investment Casting of High Performance Turbine Blades by Liquid Metal Cooling - A Step Forward Towards Industrial Scale Manufacturing", (Paper presented at the Int. Symp. on Liquid Metal Proc. and Cast., Sante Fe, New Mexico, Feb. 1999), pp. $31-40$

9. D. Goldschmidt, "Einkristalline Gasturbinenschaufeln aus Nickelbasis-Legierungen, Teil I: Herstellung und Mikrogefüge", Mat.-Wiss. u. Werkstofftech., (1994), pp.311-320
10. M. N. Özişik, Basic Heat Transfer; (London, Mc-Graw-Hill Inc., 1981), p. 372

11. Kutateladze, S.S.; Borishanskii, V.M.; Novikov I.I.; Fedynskii, O.S.; Liquid Metal Heat Transfer; (New York Consultants Bureau, Ltd., 1959), p.73

12. P. Krug, "Einfluß einer Flüssigmetallkühlung auf die Mikrostruktur gerichtet erstarter Superlegierungen", (Ph.D. Thesis, University of Erlangen, 1998)

13. J. Großmann, "Casting Single Crystal Superalloys for Landbased Gas Turbines", (Paper presented at Superalloys 99, Gorham's Int. Business Conf., San Antonio, Texas, Nov. 1999)

14. R.T. Holt, W. Wallace, "Impurities and trace elements in nickel-base superalloys", Int. Met. Rev., (1976), 21[1], pp.1-24

15. B. Ilschner, "Diffusion und Viskosität in Metallschmelzen", Z. Metallkde, (1966) H.3, 57, pp. 194-200

16. F.W. Hinzner, D.A. Stevenson, "Kinetics of Solution in Liquid Metals. Solution Rate of Zinc, Silver, and Tin in Mercury", J. Phys. Chem, (1963), 67, pp. 2424 ff.

17. W. Helber, "Über die Auflösung von Chrommetall und tiefgekohltem Ferro-Chrom in Eisenschmelzen", (Ph.D. Thesis, University of Aachen, Germany, 1969)

18. O. Kubashewski, C.B. Alcock, Metallurgical Thermochemistry, (Frankfurt a.M., Pergamon Press, 1979), pp. $358 \mathrm{ff}$.

19. R.I.L. Guthrie, Engineering in Process Metallurgy, (Oxford, Clarendon Press, 1989), p. 438 